\title{
Hacia una modelización teórico-económica del terrorismo y de sus consecuencias y paliativos*
}

\section{Towards an economic-theoretical modeling of terrorism, its consequences and palliative measures}

\author{
Juan Urrutia Elejalde \\ Universidad Carlos III \\ Presidente del Patronato de la Fundación Urrutia Elejalde
}

RESUmen. Cuando la evolución de las pautas de conducta de los miembros de una población lleva a la generación de grupos identitarios, ciertas consideraciones políticas pueden llevar a la producción de un odio entre ellos que desemboque en terrorismo. El entronque de la producción de odio y terrorismo en un marco de equilibrio general permite no sólo una cierta incursión en la relación entre Economía y Filosofía que clarifica, entre otras cosas, las dificultades de la cuantificación de los efectos económicos del terrorismo, sino además examinar ordenadamente algunas de las medidas paliativas que se han propuesto incluida la controvertida mediación. Asimismo se arguye la independencia entre terrorismo y nacionalismo.

Palabras clave: Terrorismo, identidad, fraternidad, odio, mediación, nacionalismo.
ABSTRACT. When the evolution of the behavioral rules of members of a certain population carries with it the emergence of identity groups, certain political considerations may lead to the production of a class of hatred that ends up in terrorism. The grafting of hatred and terrorism into a framework of general equilibrium gives room not only to the indulging into the relationship between Economics and Philosophy which clarifies, among other things, the difficulties faced by any quantification of the economic effects of terrorism, but also to orderly examine some of the palliative measures which have been proposed including the much debated mediation. The independence between terrorism and nationalism is also underlined.

Key words: Terrorism, identity, fraternity, hatred, mediation, nationalism.

\section{Introducción}

En las páginas que siguen se persigue establecer las bases para perfilar una modelización teórico-económica del fenómeno del terrorismo, una tarea nada sencilla. Lo que la hace difícil es, en primer lugar, la ambigüedad del fenó-

* Este trabajo recoge partes de todo lo que su autor ha escrito al respecto tanto en $L a$ Mirada del Economista (Urrutia 2005, Sección 2, pp. 127-168) como en Expansión o directamente en la Red y avanza un poco más ubicando el fenómeno en un posible marco analítico que permite una cierta unificación, todavía incompleta, y alguna extensión. 
meno y, en segundo lugar, la auto-impuesta obligación de prescindir de aspectos (como el sociológico, el psicológico, el político, el ético o el literario ${ }^{1}$ ) que parecerían centrales y ello a fin de no distraer la atención de los aspectos teórico-económicos.

Esta última restricción a la teoría económica no es inocua pues, aunque hay una relativamente abundante literatura económica sobre el terrorismo bien presentada y clasificada por Llussá y Tavares (2007), la parte más importante de esa literatura se refiere a la cuantificación de los efectos económicos, presumiblemente perversos, de la actividad terrorista sobre el PIB. Sin embargo, parecería que semejante cuantificación por muy valiosa que sea, y lo es en algunos casos, estará coja mientras no se puedan utilizar los precios sombra asociados a una asignación óptima (puesto que esta es la única forma de asegurarnos que estamos midiendo los efectos sociales) y estos precios sombra sólo pueden conceptualizarse a partir de una modelización de equilibrio general, tan somera como se quiera, de un sistema económico en el que aparece el terrorismo como una de las actividades que se lleva a cabo en su seno. Se trata, pues, de dar un paso hacia la conceptualización económica del terrorismo similar, aunque mucho más modesto, al que hace más de cuarenta años dio Becker (1968) en relación al «crimen y castigo» en general.

Esta tarea, como ya ha quedado dicho, se ve dificultada por la aparente imposibilidad de ofrecer una definición no ambigua del terrorismo. De la Calle y Sánchez Cuenca (2011) han ofrecido una minuciosa descripción de las ambigüedades que surgen una vez que queremos hacer coincidir una definición que atienda a los medios utilizados con otra que preste atención a los autores. En sentido estricto nos gustaría restringir la atención a actos violentos perpetrados por agentes no militares mediante el uso de medios no propiamente bélicos. Ese trabajo se limita por lo tanto a examinar un fenómeno que a veces se ha definido como un arma del débil caracterizada por el uso sistemático de la violencia física, o de su amenaza, en pos de la consecución de objetivos políticos y contra civiles inocentes.

A pesar de estas restricciones en el tratamiento, el intento de modelización teórico-económico del fenómeno que nos ocupa no puede ser simple pues no parece fácil o adecuado tratar a la violencia terrorista como un «bien» más que se produce por quien sabe hacerlo y se especializa en su elaboración

${ }^{1}$ Una visión panorámica útil es Reinares (1998). En cuanto a los aspectos sociológico y antropológico dos buenas lecturas son, respectivamente, Wieviorka (2005) y J. Zulaika y W. Douglas (1996). Para hacerse una idea de los aspectos politológicos Sánchez Cuenca y De la Calle (2009) es bastante útil. Los aspectos éticos o filosóficos en general así como los psicológicos están mezclados en, por ejemplo, los siguientes títulos además de los que se mencionarán en el cuerpo de este texto. Las contribuciones de Habermas y Derrida pueden seguirse con provecho en el ensayo de Borradori (2003) y casi todos los aspectos psicológicos se entreven fácilmente en las piezas semiliterarias como las de Glucksmann (2002), o directamente literarias como las de Semprún (1998), Lertxundi (2010) y Schlink (2011). 
con vistas a intercambiarlo por otros bienes en los mercados libres que, según la teoría económica, funcionan precisamente por la ausencia de violencia y funcionan de manera socialmente óptima por la ausencia de esas externalidades que difícilmente podemos suponer ausentes en presencia de la actividad terrorista.

Para evitar esa simpleza el trabajo consiste en un acercamiento cauteloso al asunto a partir de una situación inicial imaginada en la que el ser humano vive en un humus cultural en el que, por ciertas razones a explicar, impera el odio, odio que se traduce en agresiones predatorias o en venganzas reparadoras de ofensas quizá reales, quizá imaginadas. La recursividad implícita en la dinámica ofensa/venganza lleva a esperar no linealidades en el sistema y por lo tanto sorpresas; algo parecido al sistema físico que subyace a la actividad sísmica o volcánica. Estas actividades pueden ser estudiadas pero no parece puedan ser predichas con una mínima exactitud. De manera que sólo queda la persecución mediante la represión y la discusión sobre los efectos de las posibilidades de la prevención y de otras medidas paliativas.

A partir de este bastante vago planteamiento inicial, el trabajo se estructura de una forma fácil de describir. En la siguiente sección se realiza una explicación básica de un juego evolutivo con racionalidad limitada y memoria imperfecta que servirá para preparar el terreno explicando cómo surgen, de manera dinámica y no lineal, comunidades identitarias diferenciadas caracterizadas por distintas pautas de conducta y de donde puede surgir tanto la fraternidad como el odio. En la tercera sección se realiza una cierta interpretación no formal de lo que Glaeser (2005) llama economía política del odio y que sirve como posible explicación del surgimiento del odio entre distintas comunidades identitarias y la consiguiente aparición del terrorismo como violencia entre dos de ellas: una minoritaria y débil políticamente y otra mayoritaria y políticamente poderosa. A continuación se reflexiona justamente sobre la situación representada por el equilibrio general de una sociedad escindida en la que hay producción de terrorismo y externalidades obvias que justificarían las intervenciones examinadas en la sección siguiente. La quinta sección, en efecto, explora las posibles medidas paliativas en un contexto de equilibrio parcial en el que se estudia, siguiendo a Frey y Luechinger (2003 y 2004), la relación entre dos «bienes», uno agregado por un lado y el terrorismo por otro. Sabiendo de antemano que el equilibrio no es óptimo merece la pena preguntarse por las posibilidades de intervención incluyendo la mediación. La última sección resume y concluye.

\section{El vivero de memes}

Comencemos de la manera más general posible pensando que nos encontramos en un mundo único compuesto por un número indeterminado de agentes 
individuales. En este mundo cualquier convención social, desde la más simple, como usar el tenedor, a la más compleja, como puede ser un idioma, será denominada «meme» siguiendo a la analogía con los genes que inspiró Dawkins (1989) y que ha sido explorada, por ejemplo, por Blackmore (1999). La idea de vivero de memes quiere denotar el proceso evolutivo que, en ausencia de racionalidad ilimitada y con memoria limitada, basado sólo en el contacto repetido entre los individuos, trabaja hacia la emergencia de pautas de conducta de equilibrio que constituyen los memes. Como veremos, en el equilibrio de este proceso evolutivo podremos encontrar conjuntos de memes que delimitan diferentes grupos identitarios o, quizá, un solo grupo caracterizado por unos memes únicos. En lo que sigue se utiliza la formalización utilizada por Urrutia (2000) que, a su vez, está basada en D. Friedman (1991).

\subsection{El conjunto de estrategias}

Sea K el conjunto de grupos de nuestro mundo. Por simplicidad, y porque es todo lo que se necesita para este trabajo, supondremos que hay sólo dos grupos indexados por $\mathrm{K}=1,2$ y denotaremos por $\mathrm{M}_{\mathrm{k}}$ el número de individuos que forman cada grupo con $\mathrm{M}_{1}>\mathrm{M}_{2}$. Sea $\mathrm{N}$ el único conjunto de estrategias puras disponible indexadas por $\mathrm{i}=1, \ldots, \mathrm{N}$. En consecuencia el simplex N-1 dimensional.

$$
\mathrm{S}^{\mathrm{k}}=\left\{\mathrm{x}=\left(\mathrm{x}_{1}, \ldots \ldots \ldots \ldots, \mathrm{x}_{\mathrm{N}}\right): \mathrm{x}_{\mathrm{i}} \geq 0, \Sigma_{i} x_{i}=1\right\}
$$

tiene la interpretación clara de distribución de frecuencias de las estrategias puras en el grupo $\mathrm{k}, \mathrm{k}=1,2$. Denotemos por

$$
\mathrm{S}=\mathrm{S}^{1} \times \mathrm{S}^{2}
$$

el conjunto $\mathrm{s}$ de pares $\left(s_{k}^{1}, s_{k}^{2}\right)$, tal que $\mathrm{s} \in \mathrm{S}$ y en donde $s_{k}^{1}, s_{k}^{2}$ son vectores de estrategias puras que pueden entenderse como pautas de conducta que pueden llegar a ser convencionalmente aceptadas por cada miembro de cada grupo por el mero hecho de que los otros miembros también las aceptan conformando en ese caso lo que llamamos memes.

\subsection{Consideraciones estáticas}

Sobre el conjunto $\mathrm{S}$ podemos ahora explicitar la función de pagos y el equilibrio, ambos estáticamente considerados. Sea:

$$
\begin{gathered}
f:\left(S^{1} \times S^{2}\right) \rightarrow R^{k} \quad \text { y t.q. } \\
f(S, S)=\left(f^{1}\left(s_{1}, S_{2}\right), f^{2}\left(S, S_{2}\right)\right),
\end{gathered}
$$

de forma que:

$$
f^{k}:\left(s^{k} \times s\right) \rightarrow R
$$


es la ganancia del grupo k cuando este grupo adopta el vector de estrategias $s_{1}^{k}$ y el otro grupo adopta $s_{2}^{k}$.

Con relación a esta función de pagos estática podemos considerar dos nociones de equilibrio del juego estratégico jugado por todos los agentes de nuestro mundo. En primer lugar un equilibrio de Nash para $f$, NE $(f)$, se puede definir de la siguiente forma:

$$
\begin{gathered}
S=\left(s^{1}, s^{2}\right) \text { es un NE }(f) \text { si } \\
f^{k}\left(x, S^{k}\right) \leq f\left(s^{1}, S^{2}\right), \forall x \in S^{k}, \mathrm{k}=1,2
\end{gathered}
$$

En este equilibrio podemos decir que, en cualquiera de los grupos, $\mathrm{k}=1,2$, la distribución de frecuencias de equilibrio nos da la mejor respuesta débil de un individuo del grupo frente a las estrategias de cualquier otro. En segundo lugar podemos definir una segunda noción de equilibrio que se denomina estrategia evolucionariamente estable para $f$, ESS $(f)$ si para $\mathrm{k}=1,2 \mathrm{y}$ para todo $\mathrm{x} \neq \mathrm{s}^{\mathrm{k}}$ tenemos que:

$$
\begin{array}{r}
\text { O bien } f^{k}\left(x, s^{2}\right)<f^{k}\left(s^{1}, s^{2}\right) \quad \forall \mathrm{k}=1,2 \\
\text { O bien } f^{k}\left(x, s^{2}\right)=f^{k}\left(s^{1}, s^{2}\right) \quad \forall \mathrm{k}=1,2 \\
f^{k}\left(x^{1}, x^{2}\right)<f^{1}\left(s^{1}, x^{2}\right) \\
f^{2}\left(x^{1}, x^{2}\right)<f^{2}\left(x^{1}, x^{2}\right)
\end{array}
$$

Es decir, el conjunto de estrategias $s \in S$, un vector para cada grupo, pertenece a ESS $(f)$ si es un NE $(f)$ estricto o, si no siéndolo, no hay ningún otro par de vectores de estrategias, un para cada grupo, o distribución de frecuencias de estrategias $\left(\mathrm{x}^{1}, \mathrm{x}^{2}\right)$ que sea $\mathrm{NE}(f)$. La interpretación que se suele dar de esta noción de equilibrio, es que es tal que no existe ningún pequeño grupo de mutantes (es decir, cambios entre la distribución de frecuencias de las estrategias disponibles) que puede invadir una comunidad en el sentido de hacer cambiar las pautas de conducta del equilibrio alcanzado.

Dejemos sentado de momento que, como es obvio por las definiciones,

$$
\operatorname{ESS}(f) \subset \operatorname{EN}(f)
$$

\subsection{Consideraciones dinámicas}

Pasemos ahora a considerar la dinámica que genera la evolución de los memes o distribución de frecuencias. Para describir la dinámica de las estrategias individuales, en nuestra interpretación de la distribución de frecuencias, suponemos que en cada período de tiempo los miembros del mundo son emparejados estocásticamente para jugar, una o varias veces, el juego estático ya descrito. Al final de este lapso de tiempo cada individuo ha aprendi- 
do algo respecto a la distribución existente de las estrategias (de sus frecuencias) y de sus resultados relativos. Frente a una nueva ronda de contactos, cada agente utilizará este conocimiento adicional para decidir su comportamiento aunque no suponemos racionalidad limitada ni memoria perfecta. Veamos, sea

$$
\mathrm{F}: \mathrm{S} \rightarrow R^{N K}
$$

t.q.

$$
\mathrm{F}(\mathrm{S})=\mathrm{s}=\left[\mathrm{s}^{1}, \mathrm{~s}^{2}\right]
$$

en donde

$$
S^{k}=\left[\begin{array}{lllll}
s_{1}^{k} & \ldots & \ldots & \ldots & S_{N}^{k}
\end{array}\right], \quad \mathrm{k}=1,2
$$

Esto es una descripción genérica de la dinámica que lleva de una distribución de frecuencias de las estrategias a otra. Hay muchas formas de especificarla y en general responderán siempre de una u otra manera a la perfomance relativa observada. Aquí restringiremos la atención a dinámica $\mathrm{F}$ compatible con la función de pagos $f$ ya descrita y la denotaremos por $\mathrm{F}_{\mathrm{f}}$. Podemos también aquí distinguir dos nociones de equilibrio, ahora dinámico. Podemos decir que una distribución de frecuencias (o meme) s es un punto fijo de $\mathrm{F}_{\mathrm{f}}, s \in \mathrm{FP}\left(\mathrm{F}_{f}\right)$ si $\mathrm{F}(\mathrm{s})=0$. Entre estos equilibrios podemos singularizar aquellos que son asintóticamente localmente estables. Los denotamos por $s \in \mathrm{EE}\left(\mathrm{F}_{f}\right)$ y los denominamos equilibrios evolutivos de $\mathrm{F}_{\mathrm{f}}$. Es obvio que EE $\left(\mathrm{F}_{f}\right) \subset \mathrm{FP}\left(\mathrm{F}_{\mathrm{f}}\right)$. Podemos afirmar, siguiendo a Friedman (1991), que

$$
\mathrm{EE}\left(\mathrm{F}_{f}\right) \subset \mathrm{NE}(f) \subset \mathrm{FP}\left(\mathrm{F}_{f}\right)
$$

y que muy a menudo

$$
\operatorname{ESS}(f) \subset \operatorname{EE}\left(\mathrm{F}_{f}\right)
$$

Cuál de estos equilibrios dinámicos se alcanzarán, depende, naturalmente, de la cuenca de atracción de ese equilibrio. B (s) en donde s es el equilibrio dinámico de que se trate.

\subsection{Multiculturalismo, pluralismo, fraternidad y complejidad ${ }^{2}$}

Si concentramos nuestra atención en un equilibrio evolucionariamente estable, nos topamos con que puede haber grupos de individuos caracterizados por memes específicos de ese grupo, de forma que en el equilibrio podamos hablar de grupos distintos, o que toda la población del mundo haya llegado a alcanzar los mismos memes. Para nuestra finalidad en este trabajo nos cap. 3).

${ }^{2}$ Este apartado está basado en Urrutia (2005), en Urrutia (2008a) y en Urrutia (2005, 
interesa como punto de partida el caso asimétrico. Para bajar un poco a tierra pensemos que estamos en una sociedad en que tenemos dos grupos, el mayoritario y poderoso y el minoritario y débil políticamente. Es posible que el grupo mayoritario tenga una mayoría relativa de individuos individualistas y el minoritario muestre una mayoría relativa de individuos cooperativos. Es un ejemplo simple; pero sólo trato de aclarar la posibilidad de subgrupos caracterizados por pautas de conducta distintas que no pueden ser variadas fácilmente y cuya mera existencia plantea problemas que podíamos llamar políticos. Una sociedad mixta nos puede confrontar con el multiculturalismo, cuando no hay contacto entre los subgrupos que, por otro lado, pueden vivir libremente según los memes elegidos o el pluralismo, cuando hay contacto entre esos subgrupos. Se trata de distintos grados del relativismo cultural que se plantean en un mundo global donde la inmigración es frecuente. El R.U. ha optado por el multiculturalismo, mientras Alemania ha optado por el pluralismo. La primera estrategia genera una diversidad cultural que puede ser buena en sí misma siempre que la ratio individualistas/cooperativistas sea adecuada a la estructura productiva del grupo; pero que también puede generar una competencia identitaria que desemboque en el odio, tal como veremos en la siguiente sección. La segunda estrategia política deja espacio a que la evolución continúe hacia el mestizaje y la homogenización de las pautas de conducta hasta quizá alcanzar lo que en otro lugar (Urrutia 2000) llamé fraternidad y que está constituida por un equilibrio evolutivo simétrico en el que la distribución de frecuencias de las estrategias es la misma para ambos grupos. Después de lo dicho en los apartados previos de esta sección debería estar claro que la fraternidad no es sólo algo así como el cemento de la sociedad (Elster 1989) o el caldo de cultivo imprescindible para el trabajo de la Libertad y la Igualdad (Domènech 1993), sino algo más específico ejemplificado por algunas características propias de un juego evolutivo que se juega en tiempo real (no virtual), con racionalidad limitada y sin memoria perfecta. Esta clase de juegos sirven para entender cómo emergen pautas sociales de conducta (convenciones, costumbres o instituciones) que, al ser de equilibrio, todos aprendemos a esperar. Esta confianza en que los demás actuarán según estas pautas induce una confianza mutua que denomino fraternidad.

Antes de pasar a la siguiente sección conviene reflexionar con un poco de atención sobre esta noción de fraternidad y de su relación con la complejidad pues ambas juegan un papel en este intento de sobrepasar las dificultades asociadas al fenómeno del terrorismo. Como hemos visto, en el proceso de generación de pautas de conducta nos encontramos con agentes heterogéneos que interactúan entre sí y que acaban recibiendo el impacto de sus propias acciones a través de la influencia de éstas en las acciones de los demás. Estos sistemas dinámicos recursivos adolecen de no linealidades que hacen de ellos algo difícil de predecir bien porque el equilibrio configura un 
atractor extraño, bien porque pequeños cambios en las condiciones iniciales acarrean cambios enormes en la solución. En la medida en que un algoritmo de solución necesitaría muchos pasos para computarla decimos que estos sistemas dinámicos son complejos. Por lo tanto, y en la medida en que la fraternidad se plasma en un sistema dinámico no lineal, podemos decir que ésta, la fraternidad, acarrea complejidad.

Para profundizar en la relación entre fraternidad y complejidad comparemos dos formas de ajedrez que, aunque no son juegos evolutivos, ilustran la importancia de la racionalidad limitada y de la memoria imperfecta en las interacciones en tiempo real.

Pensemos primero en un ajedrez virtual en el que se han calculado, y publicado, todas las ramas posibles de cualquier árbol de jugadas a partir de cualquier movimiento inicial: no hay fallos de inteligencia ni falta de memoria. Se sabe que, en estas condiciones, las blancas siempre ganan. No hay pues complejidad, pero tampoco, claro está, fraternidad: dos jugadores nunca se sentarían a jugar este ajedrez virtual. Contrastemos esto con el ajedrez real. En base a nuestra racionalidad limitada, y a nuestra incapacidad para recordar todos los análisis previos, movemos pieza, en el límite de tiempo concedido, más o menos a ver qué pasa. El resultado es que puede pasar cualquier cosa y que encontrar la solución (lo que va a pasar) exigiría un algoritmo muy largo. Hay pues complejidad y la gente se hermana para jugar este juego dándose la mano al principio y al final.

Si concebimos el mundo de la interacción entre las personas a la manera del ajedrez virtual, la fraternidad no es concebible y, notemos, el terrorismo, si necesitara de justificación, la buscaría en una tal concepción del mundo. Si, por el contrario, pensamos el mundo como un ajedrez real, el terrorismo se nos aparece precisamente como rompiendo la fraternidad mediante una patada al tablero. Esta segunda forma «aristotélica» de ver las cosas contrasta con la forma «kantiana» primera en donde reina la obscenidad de la transparencia y en donde se acaba admitiendo, con Sartre, el dolor en aras de algún principio universal abstracto. En efecto, en el mundo «aristotélico» propio de la fraternidad hay pudor y si hay que elegir entre una madre y la Justicia, se elige, con Camus, a la madre.

Estas consideraciones me llevan a cuatro afirmaciones que me resultarán cruciales cuando, más adelante, trate de pensar formas de lucha contra el terrorismo. Quiero pues afirmar que el terrorismo es una simplificación intolerable del presunto problema que subyace a su génesis y a su pervivencia; que la lucha contra el terrorismo exige la afirmación de la complejidad; que, a veces, la ambigüedad puede ser, no el pecado de un antidemócrata, sino el ineludible reflejo de la complejidad que acompaña a la fraternidad y que, finalmente, no es en el terreno de los principios donde vamos a vencer al terrorismo, sino en el terreno de la «decencia», algo que, desde el pragmatismo rortyano, debemos admitir que es relativo. 


\section{Economía política del odio}

Imaginemos pues que el mundo que hemos descrito ha alcanzado un equilibrio evolucionariamente estable asimétrico. Nos encontramos pues con un grupo mayoritario identificado por una cierta distribución de las estrategias disponibles y un grupo minoritario caracterizado por una distribución alternativa de esas estrategias. Por ejemplo, el grupo mayoritario que es el poderoso puede ser mayoritariamente blanco y relativamente rico mientras el minoritario y débil políticamente puede ser mayoritariamente negro y relativamente pobre. En una situación así es posible que los memes que caracterizan a uno u otro grupo serán diferentes. En el primer grupo jugarán más a cricket y menos al baloncesto y mantendrán a sus hijos más tiempo formándose que el otro grupo. Éste es el posible origen del odio entre los miembros del segundo grupo hacia los miembros del primero o viceversa. El detonador del odio será seguramente la creación de mitos falsos o leyendas sobre los memes ajenos si con ello se puede convencer a una mayoría de votantes de votar a favor de quien hace circular el mito. Como dice Glaeser (2005), a quien en esta sección trato de resumir y simplificar, los igualitaristas estarán tentados de generar odio contra las minorías ricas y los contrarios a las políticas redistributivas tratarán de denigrar a las minorías pobres, haciendo surgir el odio. Este autor arguye que el antiamericanismo está basado a veces en el odio a la presente criminalidad de los americanos elaborada como mito por islamistas, que el antisemitismo surge en base a cuentos sobre las atrocidades de los judíos elaborados por los nazis y que el odio a los negros en el sur de los EE.UU. se basa en la presunta amenaza que pueden representar a las mujeres blancas mayoritarias en ese territorio. El 11-S, el Holocausto o las acciones del $\mathrm{Ku}$ Klux Klan son ya actos criminales, terroristas diríamos, que surgen de la repetición de esos falsos mitos que sólo persiguen ventaja en la administración del poder. Estos casos obvios hacen pensar que el terrorismo puede tener su origen en el odio. De ahí que merezca la pena explorar ese origen en un contexto con mayor estructura política que la inexistente de la sección anterior.

Pensemos en esta estructura política mediante la descripción de cuatro momentos importantes en el juego del poder. En un primer momento los miembros del grupo mayoritario que detenta el poder han de decidir si elaborar o no un mito que toma al grupo minoritario como chivo expiratorio de los errores cometidos desde el poder y que ponen en peligro la continuidad en el mismo. En un segundo momento todos reciben señales sobre la verdad del mito y cada uno decide si investigar esta veracidad y si tomar medidas protectoras contra el chivo expiratorio. En un tercer momento los mecanismos de otorgamiento del poder funcionan y llevan a unos u otros a su detentación y uso de forma que quien lo detente puede llevar a la práctica sus políticas preferidas. En un cuarto momento es posible que los miembros del 
grupo excluido del poder puedan tomar represalias contra quienes les han demonizado.

En este contexto y mediante un abuso del lenguaje podemos hablar del «mercado del odio». La oferta de odio viene dada por la creación de un mito por los políticos en el poder pertenecientes en su mayoría al grupo mayoritario, mito que denigra a los miembros del grupo minoritario y su identidad memética, con la finalidad de continuar ocupando el poder de que se trate en cada caso. Estos «empresarios del odio» como les llama Glaeser pueden elaborar, mediante un coste $\mathrm{K}$, una historieta que achaca a los miembros del grupo minoritario unas conductas que serían la causa de la desafección de los que les podrían otorgar el poder. No hay una demanda de odio propiamente tal, pero podemos legítimamente preguntarnos por las razones que hacen que los miembros del grupo en el poder acepten su veracidad, a pesar de señales encontradas que podrían ser desencriptadas, y por esas otras razones que les llevarían o no a la adopción de medidas de protección a un coste $\mathrm{Z}$ en caso de no atender a las señales.

\section{1. «Demanda» de odio}

Veamos para empezar cómo se determina, a la luz de las señales disponibles sobre el grupo minoritario pretendidamente culpable de ciertos males, la decisión de investigar su veracidad y de tomar medidas de autoprotección.

Supongamos que el grupo minoritario es dañino con probabilidad $\theta$ y es perfectamente inocuo con probabilidad $1-\theta$. Si de hecho fuera dañino causaría un daño de dỹ $\tilde{y}_{0}, \mathrm{~d}>0 \mathrm{y}$ donde $\tilde{\mathrm{y}}_{0}$ es la renta media de los miembros del grupo mayoritario caracterizado por los memes que en él han surgido. Además se reciben señales sobre la malignidad del grupo minoritario. Suponemos que sólo caben señales confirmatorias de su maldad. Si no surgieran señales de ningún tipo todos saben que ese grupo minoritario presuntamente nocivo no lo es (con probabilidad $1-\theta$ ) a no ser que los detentadores del poder elaboren una señal inventada confirmatoria de su maldad, cosa que hacen con probabilidad $\varphi$. Por lo tanto, dados los prejuicios y el mito confirmatorio, la probabilidad de que el grupo minoritario funcione con unos memes dañinos para la comunidad es:

$$
\frac{\theta}{\theta+\varphi(1-\theta)}
$$

en caso de que se reciban señales que, como hemos supuesto, son confirmatorias de los prejuicios. Sin embargo, si no se recibe ninguna clase de señal distinta de las inventadas los prejuicios se disipan y la probabilidad que se asigna a la maldad del grupo minoritario sigue siendo $\theta$. 
Ahora estamos en disposición de calcular para qué valores de los parámetros se buscará información por parte de un miembro del grupo en el poder a un coste $\mathrm{Z}$ y en qué condiciones comprará, a un coste $r$, una protección que reduce el daño desde dỹ ${ }_{0}$ hasta $\delta$ dỹ $\tilde{y}_{0}$. Eliminemos de raíz este último problema suponiendo por simplicidad que:

$$
\frac{\theta}{\theta+\varphi(1-\theta)} d \tilde{y}_{o}>r
$$

de forma que comprar protección siempre merece la pena. Si no se gasta nada en adquirir información el coste esperado por un miembro del grupo mayoritario es:

$$
\frac{\theta}{\theta+\varphi(1-\theta)} \delta \mathrm{d} \tilde{y}_{o}+r
$$

Si se busca la información que puede aclararnos la naturaleza del grupo minoritario, ese coste esperado es o bien nulo, si la señal confirmada resulta ser falsa ya que en ese caso sabemos que el grupo minoritario no es malo, o bien $\delta$ dỹ $\tilde{y}_{0}+r$ si la señal confirmatoria resulta ser verdadera. Luego el coste esperado total de buscar y adquirir información es:

$$
\frac{\theta}{\theta+\varphi(1-\theta)}\left(\delta \mathrm{d} \tilde{y}_{o}+r\right)
$$

de manera que la ganancia de buscar y adquirir información es:

$$
\frac{\varphi(1-\theta)}{\theta+\varphi(1-\theta)} r
$$

Luego, siempre que $\mathrm{Z}$ sea menor que esta cantidad se llevará a cabo por parte de un individuo del grupo mayoritario una labor de información sobre las características identitarias del grupo minoritario.

Podemos ahora irnos aproximando al surgimiento del odio en la población mayoritaria. Sea $f(z)$ la función de distribución del coste de búsqueda y $\mathrm{H}(\mathrm{z})$ la correspondiente función acumulativa. Denotamos por:

$$
\mathrm{H}\left[\frac{\varphi(1-\theta)}{\theta+\varphi(1-\theta)} r\right]
$$

la proporción del grupo mayoritario que cree, con probabilidad 1, que el grupo minoritario es realmente dañino. Si ese grupo realmente fuera dañino, nadie gastará recursos en fabricar y difundir el libelo denigratorio porque la 
gente recibirá en cualquier caso alguna señal confirmatoria de su maldad pues recordemos que hemos eliminado por hipótesis las señales favorables. $\mathrm{Y}$ en consecuencia todo el mundo se protegerá. Pero este caso no tiene interés pues contesta a la pregunta sobre las condiciones de búsqueda de información de manera simple y abrupta. Suponemos por lo tanto que el grupo minoritario y sospechoso es realmente inocente. En este caso:

$$
1-\mathrm{H}\left[\frac{\varphi(1-\theta)}{\theta+\varphi(1-\theta)} r\right]
$$

es la proporción de miembros del grupo mayoritario que cree que el grupo minoritario es malo con probabilidad $\theta /(\theta+\varphi(1-\theta))$. Estos agentes son los que habiendo recibido una señal no tratan de examinar su veracidad y les gustaría eliminar o disminuir la influencia perniciosa del grupo minoritario. Estos agentes son los odiadores. Existen odiadores y odiados porque los empresarios del odio producen los mitos falsos. Pero, ¿en qué condiciones surgirán estos empresarios?

\subsection{Oferta del odio}

Supongamos, por simplicidad una vez más, que la única variable sobre la que gira el contencioso es la renta $(y)$ aunque podríamos entenderla como «poder» genérico tratamos de entender cómo y cuándo el grupo mayoritario y poderoso decide construir y diseminar un mito falso sobre los miembros del grupo minoritario que torpedean las políticas que ellos desean ver puestas en práctica, sean éstas, por ejemplo, la redistribución de la renta o la descentralización del poder. Sea K el coste de fabricar y diseminar el mito. Se trata de una variable no directamente observable y que sigue una función de distribución $f(\mathrm{~K})$ y una acumulativa de $\mathrm{F}(\mathrm{K})$. Sea p la proporción de la población total que pertenece al grupo minoritario y $(1-\mathrm{p})$ la proporción correspondiente al grupo mayoritario.

Imaginemos ahora que la renta o el poder está distribuido en cada grupo, mayoritario o minoritario, de la siguiente forma. Para el grupo mayoritario, $\mathrm{M}$, o poderoso o centralista

$$
f_{M}(y) \quad y F_{M}(y),
$$

Y para el grupo minoritario, $\mathrm{m}$, o débil o descentralizador

$$
f_{m}(y) \quad y \mathrm{~F}_{m}(y)
$$

y sea $\Delta_{\mathrm{y}}$ la diferencia entre rentas medias de ambos grupos.

Pensemos que hay una especie de tasa implícita de redistribución de la renta entre los dos grupos que, además, puede verse como una «proxy» para el poder decisorio de uno $u$ otro grupo. Pensemos por concreción que $\tau_{R}$ es 
la tasa propuesta por el grupo pro redistributivo que coincide con el centralizador y que $\tau_{\mathrm{A}}$ es la tasa propuesta por el grupo antirredistributivo que coincide con el descentralizador y supongamos que $\tau_{\mathrm{R}}>\tau_{\mathrm{A}}$. Las transferencias netas dependen de estas tasas y de las rentas medias de ambos grupos:

$$
\left(\tau_{\mathrm{R}}-\tau_{\mathrm{A}}\right)\left(y_{M}-y_{m}\right)
$$

A partir de aquí, Glaeser prueba que al grupo mayoritario le conviene generar y diseminar odio si y solo si $\Delta_{\mathrm{y}}<0$, es decir, si la renta media del grupo minoritario (o su poder) es mayor que la del grupo mayoritario o su poder.

Para terminar sólo hay que entender cómo ese odio generado en el caso de $\Delta_{\mathrm{y}}<0$, se convierte en terrorismo o podría hacerlo más acá de argumentos étnicos, sociológicos o psicológicos. Si pertenezco al grupo minoritario caracterizado por ciertos memes y me odian tengo tentación de odiar al grupo mayoritario caracterizado por otros memes; pero si este grupo, que es el que detenta el poder, es redistributivo de renta o poder, me conformo y no transformo mi odio al odiador en terrorismo. Pero si el segundo grupo, el que detenta el poder, es redistributivo o centralizador, el odio al odiador por parte del grupo minoritario puede transformarse en terrorismo pues no siente el paliativo que existe en el caso anterior.

\subsection{Nacionalismo y terrorismo ${ }^{3}$}

Aquí podría terminar esta posible explicación del terrorismo como «odio en acto»; pero, antes de pasar a considerar este terrorismo en el marco del equilibrio general de una economía de mercado, conviene disipar una idea muy extendida que pretende que el nacionalismo sería el caldo de cultivo del terrorismo. Veamos si, a la luz de la idea de fraternidad (o teleia philia aristotélica) que ya ha aparecido en la sección anterior, esta asociación es sostenible. El marco de análisis que se ha adoptado en este trabajo facilita la reflexión a ese respecto. Esto es así puesto que, tal como se expresa en la sección 2, en el equilibrio del juego evolutivo que allí se considera, es posible que la población de un estado determinado quede dividida en dos grupos o en general varios, cada uno caracterizado por aquellas propias pautas de conducta de equilibrio que denominamos «memes». Pues bien, el nacionalismo como ideología política surge cuando su base social no coincide con la del Estado que lo engloba.

Comencemos nuestro análisis por reconocer que el nacionalismo, como producto cultural, es hoy una fuente de inspiración sobre alternativas de convivencia tan rica como el liberalismo. Este último nos ha llevado a pensar que el «tamaño del Estado» ha de tener unos límites más allá de los

${ }^{3}$ Este apartado reproduce el idéntico apartado de Urrutia (2005). 
cuales se colapsa. La crisis del Estado del Bienestar parecería confirmar la adecuación de este pensamiento. El nacionalismo sugiere que la «extensión del Estado» podría también tener límites, tal como se colige de la lectura del libro de Alesina y Spolaore (2003). Las dificultades en la construcción de la UE constituiría un ejemplo que corrobora la pertinencia de esta sugerencia. El prestigio actual o renovado de estos dos productos culturales acarrea el desprestigio de la noción de Estado que, como instancia capaz de organizar la convivencia, parece tener escaso recorrido.

En consecuencia los signos tradicionales del nacionalismo pierden virulencia. El sustrato étnico, la diferenciación cultural (especialmente lingüística) y la connotación épica de un David luchando contra un Goliath ya no son algo necesario y permanente, sino algo contingente y precario. No serían sino la realización en un momento determinado del amplio proceso evolutivo ya examinado y que deshace y reconfigura grupos humanos identificados, más que por la etnia, por distintos rasgos culturales (incluido, cómo no, el lenguaje) y que difícilmente pueden verse como davides guerreros. En la imaginería cultural del momento ya no hay goliaths contra los que luchar, sino sólo davides con los que convivir.

En estas condiciones no parece tan evidente como a veces se considera sostener la relación entre nacionalismo y terrorismo. Pero remachemos esta independencia. Se ha matado por la Libertad y por la Igualdad y en su nombre se han producido guerras y revoluciones. Éstas han generado siempre una violencia que, aun siendo terrible, ha solido ser paliada por la Fraternidad. Quiero entender que el terrorismo es una especie de violencia que no puede ser aliviada por la fraternidad porque ataca, y mata, precisamente esa fraternidad.

El terrorismo mata la Fraternidad porque los agentes individuales, envueltos en un proceso magmático de experimentación de pautas de conducta, no pueden actuar genuina y auténticamente según sus propios impulsos, sino que actúan mediatizados por el terror, eliminando cualquier expectativa de que los demás seguirán actuando como lo hacen e impidiendo así la emergencia de pautas de conducta estables que puedan sostener la confianza mutua. Los hermanos se convierten en espías.

En consecuencia se sigue, creo yo, que el terrorismo ataca sobre todo cualquier proyecto político que tenga algo de nacionalista. Esto es así porque si el nacionalismo respetable pudiera estar basado en alguna idea moderna (y aunque para ser respetable no necesite de basamento intelectual alguno) lo estará en ideas como la de Comunidad (propia del pragmatismo de Rorty), muy próxima a la de fraternidad, tal como se la entiende aquí. 


\section{Perspectiva de equilibrio general}

Una vez caracterizada la sociedad que estamos considerando como una en la que hay diferencias identitarias, hemos de introducir el sistema político y económico que la hace funcionar. Ya hemos visto cómo la convivencia se regula mediante un cierto sistema político único que no hace falta especificar más allá de los rasgos mínimos que han sido necesarios para entender el surgimiento del odio y la producción de terrorismo.

En cuanto al sistema económico la más sencilla de las hipótesis en este intento de modelización es suponer que se trata de un sistema de mercado en el que unos cuantos productores producen bienes y los ponen en el mercado persiguiendo su beneficio mientras los consumidores utilizan su renta (que habrán conseguido trabajando en la producción) comprendo aquellos bienes que maximizan su utilidad. El equilibrio de un sistema tal es una asignación de bienes y unos precios a los cuales cada agente, productor o consumidor, maximiza su función objetiva, beneficio o utilidad, y los mercados se vacían a esos precios de equilibrio.

Recordemos brevemente lo que se ha llamado el primer teorema del bienestar. Esa asignación de equilibrio resulta ser una asignación socialmente óptima (y denominada óptima de Pareto) en el sentido preciso que no existe ninguna otra que sea preferida unánimemente. Este teorema crucial es cierto en condiciones específicas. Por un lado, es necesario que existan todos los mercados, incluidos los contingentes y los de futuro, y, por otro lado, es también necesario que no haya externalidades, es decir, que no haya ningún efecto sobre las funciones objetivas de los agentes que se deriven de una actividad que no pase por el mercado. En la práctica ninguna de estas dos condiciones se dan, por lo que ahora deberemos examinar qué podemos decir, en condiciones realistas, de esa asignación de equilibrio y de sus precios asociados cuando la actividad terrorista constituye un sector económico más con agentes que lo producen y agentes que lo consumen al menos en el sentido de convivir con él pagando quizá protección.

En esta sección pasaremos ahora revista a algunas de las consecuencias que acarrea la estructura incompleta de mercados. En primer lugar examinaré algunas opiniones filosóficas surgidas a partir del 11-S-2001 a la luz de la conceptualización de esa estructura incompleta en general. En segundo lugar y más en concreto merece la pena examinar una posible extensión de la estructura de mercados mediante el establecimiento de mercados de futuro sobre actos terroristas. En tercer lugar explicitaré una implicación importante de la no optimalidad de la asignación de equilibrio: los precios a ella asociados no reflejan el coste social de las cantidades producidas y consumidas por lo que, en principio, es difícil utilizarlos para calcula el coste social del terrorismo. 


\subsection{Estructura incompleta de mercados: una incursión filosófica ${ }^{4}$}

A pesar de que en la introducción expresé mi determinación de abstraerme de cualquier planteamiento distinto del económico, en este punto creo de interés mencionar dos trabajos filosóficos relacionados con el ataque a las torres gemelas que pueden ayudarnos a comprender la naturaleza de este nuevo terrorismo internacional y al mismo tiempo a profundizar en la concepción teórico económica de equilibrio general de esta sección.

El primer trabajo al que me quiero referir es «L'esprit du terrorisme» que Jean Baudrillard publicó el 3 de noviembre de 2001 en Le Monde y que muy recientemente ha editado Galilée. De entre sus sugerencias siempre perceptivas me gustaría destacar dos. Por un lado, el carácter suicida del ataque cambia las reglas del juego o más bien las elimina completamente. Para Baudrillard esto no sería sino el estiramiento hasta la crispación total de una tendencia que observamos en la sociedad ya que, de hecho, el hundimiento de las torres, como algo inesperado y distinto del impacto de los aviones suicidas, simbolizaría el suicidio de nuestro sistema social que muestra directamente así su más que real fragilidad. Por otro lado, el acontecimiento vivido en directo por el mundo a través de las imágenes televisivas es un ejemplo evidente de la banalidad y transparencia del mal. El mal es algo simple y sin recovecos: destruye lo que dice querer destruir y no parece que persiga conseguir nada a cambio. A diferencia del terrorismo del siglo XX que tenía, y tiene en la medida que continúa, finalidades reales y específicas, este nuevo terrorismo del siglo XXI es pura simbología y en este sentido refleja muy nítidamente la exigencia airada de transparencia total en la conducta de las corporaciones. Pero esta transparencia total es a su vez muestra, indirecta esta vez, de la fragilidad ya mencionada del sistema económico. Una vez eliminados todos los secretos ya no hay últimas defensas, planes alternativos contingentes o ases en la manga; hay sólo lo que hay y si esto que hay se rompe no hay esperanzas de arreglo. La limpieza total nos ha dejado indefensos como una piel excesivamente frotada con agua y jabón. Pues bien esta fragilidad y esta transparencia son dos categorías que no pocos economistas asociaríamos al sistema económico al que nos acercamos poco a poco y que parece como un arriesgado número de circo efectuado sin red, es decir, como sostenido únicamente por interacción entre los propios mercados que por su parte no se sostienen en nada externo a ellos. A mi juicio no hay idea más interesante que este auto-sostenimiento del sistema de mercado; pero cuando uno lo piensa en toda su profundidad no hay más remedio que reconocer, en ausencia de otras instituciones, su fragilidad extrema simbolizada por la implosión de las torres gemelas al derretirse sus varillas arquitectónicas maestras.

\footnotetext{
${ }^{4}$ Este apartado es una incorporación cuasi verbatim de lo dicho en Urrutia (2003a).
} 
El segundo trabajo aquí relevante es Temblores de Aire. En las fuentes del terror de Peter Sloterdijk, editado por Pre-textos en el 2003 con una introducción de Nicolás Sánchez Durá. Si cito el prologuista es porque a él se debe el paralelismo entre la saturación del espacio sobre la que elucubra Sloterdijk y la conocida movilización total de Jünger. El primero nos hace ver con su espléndida retórica que el terrorismo hoy es la prolongación inevitable de la tecnología de la manipulación del medio ambiente que permite eliminar las condiciones de vida de cualquiera y de todos. Una guerra química o bacteriológica así como el nuevo terrorismo, elimina la capacidad de vivir, no apuntando directamente al cuerpo del enemigo para eliminarlo como en la guerra convencional, sino imposibilitando la vida de ese cuerpo, que por el mero hecho de respirar, actividad necesaria para la vida, aspira gas letal y se suicida. No hay pues refugio frente a esa guerra o a ese terrorismo de la misma forma que no hay abrigo en la guerra total asociada a la movilización total de Jünger: seas lo que seas estás movilizado y no te queda espacio para la persecución de tus objetivos individuales. En ambos casos, el de la saturación del espacio y el de la movilización total, no hay ni tiempo ni lugar para reflexionar y desde el que ejercer la autonomía personal. En términos de filosofía pos-moderna diríamos que no hay distinción entre el interior y el exterior, no hay nada interno, latente, oculto y por descubrir, todo está ahí fuera obscenamente alcanzable y visible como en la transparencia total.

¿Qué tiene que ver esto con la Economía? Aparentemente nada; pero hay algunas nociones abstractas profundas de la manera de pensar económica, como la racionalidad y el mercado que reciben nueva luz de estas consideraciones filosóficas. Me concentraré ahora en el mercado. Describiré la trama de lo que ha dado en llamarse estructura (in) completa de mercados, un tema complicado que, según como se explique, puede no tener nada que ver con la saturación del espacio de Sloterdijk, o con la movilización total de Jünger, o ser su más exacto correlato. La manera convencional de tratarlo comenzaría por suponer que, además del conjunto de individuos, están dados el número de mercancías y de empresas, cada una de estas últimas con su tecnología propia que especifica cómo unas mercancías de las dadas se convierten en otras mercancías de las dadas. El problema es encontrar un vector de precios, uno para cada mercancía dada, una asignación de bienes a cada consumidor y un plan de producción para cada empresa dada, tales que cada consumidor maximice su utilidad sujeta a su restricción presupuestaria y cada empresa maximice su beneficio desde su tecnología.

En esta descripción convencional la estructura de mercados es completa, es decir, todos los mercados (spot, de futuros o contingentes) están hoy operativos de forma que el tiempo no juega ningún papel $\mathrm{y}$, además, se puede mostrar que la asignación es eficiente. Si la estructura de mercados fuera incompleta, es decir, si hoy no existieran todos los mercados, el tiempo importaría, las expectativas contarían y la asignación de equilibrio no sería 
eficiente. Si ahora miramos esta descripción convencional del mercado, o del sistema de mercado, desde un punto de vista menos convencional surge una sorpresa que es la que me interesa destacar. El número y naturaleza de empresas y mercancías debería ser endógeno. Si se forma un cierto conjunto de coaliciones productivas (empresas) tendremos un cierto conjunto de mercancías; pero si se formara un conjunto distinto de coaliciones productivas el conjunto de mercancías disponibles sería distinto. En consecuencia, es instructivo reparar en que en el equilibrio el conjunto de mercancías que se producen y se consumen no es sino un subconjunto de los posibles.

En una situación así, que contraste con la convencional, cualquier cambio en gustos o en tecnología acarrea un cambio en el conjunto de mercancías disponibles. Como los cambios tecnológicos pueden ser el resultado de la labor innovadora, nos encontramos en presencia de la destrucción creativa de Schumpeter a pesar de que nos estamos moviendo en un mundo neoclásico. De acuerdo con el cambio tecnológico, algunas empresas desaparecerán mientras nacen otras que nos proporcionarán, a través de las nuevas mercancías que producen, un mayor bienestar. Pues bien, si esta mejora continua es posible, es porque no hemos agotado en la práctica el catálogo de bienes concebibles que existen en el cielo platónico; la movilización nunca es total, ni el espacio está saturado. Los terribles mundos imaginados por Sloterdijk o Jünger corresponden a la concepción convencional y nunca se harán presentes en el mundo schumpeteriano que he descrito desde una visión neoclásica aunque no del todo convencional. La destrucción creativa de Schumpeter niega, en efecto, la concepción del terrorismo elaborada por Sloterdijk. Este terrorismo de hoy es de tal naturaleza que no podemos imaginar una reserva implícita de innovaciones, todo seguirá siendo como es.

\subsection{Futuros sobre actos terroristas ${ }^{5}$}

En el verano del año 2003 nos enteramos del desmantelamiento por parte del Pentágono de planes para crear un mercado de futuros sobre actos terroristas. El examen de la iniciativa y del porqué de su retirada nos dice algo sobre la naturaleza del mercado y nos hace ver que plantearse un análisis de equilibrio general del terrorismo no es, en principio, descabellado, aunque en la práctica tiene sus limitaciones.

En condiciones ideales el mercado no sólo genera asignaciones de bienes que son eficientes en el sentido de que no hay otra unánimemente preferida; sino que además el mercado es informacionalmente eficiente en el sentido de que los precios que conforma reflejan toda la información existente distribuida de cualquier manera entre los agentes económicos. En esas condiciones ideales los precios son un estadístico suficiente al que me basta mirar

${ }^{5}$ Este apartado es una versión abreviada de lo dicho en Urrutia (2003b). 
para tomar mis decisiones sin que tenga sentido gastar recursos en buscar información adicional. En el caso del mercado de futuros que me ocupa bastaría mirar al vector de apuestas cruzadas sobre diversas contigencias terroristas para repartir de manera óptima las fuerzas de seguridad a la prevención de cada una de ellas. Pero la fascinación general por esa institución llamada mercado no debe cegarnos a lo que puede ocurrir con su funcionamiento cuando las condiciones no son ideales.

La manera más general de pensar los condicionamientos de la realidad es pensar sobre la completitud de la estructura de mercados y sobre su relación con el número de agentes que actúan en ellos. Supongamos, en primer lugar, que hay hoy un mercado para cada bien concedible a ser entregado en cualquier fecha futura en cualquier estado de la naturaleza (ampliamente definido). Sabemos que en ese caso el juego del mercado nos conduce a una situación óptima desde el punto de vista asignativo; pero también sabemos hoy que esta situación es muy frágil a no ser que el número de agentes compradores y vendedores sea muy grande en cada uno de todos esos mercados.

Si ése no fuera el caso, es decir, si cada mercado no fuera profundo (o equivalentemente muy líquido) cualquier agente tendría incentivos, o podría tenerlos, a falsear sus preferencias y a actuar de manera oportunista que, aunque resultase en un consumo mejor para él, rompería la naturaleza óptima de la asignación. Es de suponer que, en condiciones relevantes, el mercado de futuros on line que proponía el Pentágono no sería muy positivo y podría incentivar a los terroristas avariciosos a jugar en él apostando con informaciones privilegiadas para hacerse ricos al acertar con la fecha y lugar de los atentados preparados por ellos mismos, o a los terroristas generosos a utilizarlo para despistar a las fuerzas de seguridad haciendo bajar la probabilidad estimada del que se pretende realizar.

Supongamos ahora que aunque los mercados existentes fueran profundos (o líquidos) no fuera cierto que el sistema de mercado (que incluye los mercados financieros como la Bolsa o el que proponía el Pentágono) presentara una estructura completa. En ese caso es bien conocido que la asignación no es óptima y que siempre habrá alguna otra preferida por todos; pero que sin embargo no es alcanzable porque la coordinación necesaria para ello no se da debido precisamente a la ausencia de mercados.

Este resultado ha sido utilizado por los intervencionistas militantes; pero eso no nos interesa ahora. Lo que nos interesa es saber si en un caso así el mercado es informacionalmente eficiente, es decir, genera precios que reflejan toda la información existente. Es intuitivo que no será así en el caso del mercado de futuros sobre actos terroristas ya sea porque no podemos conocer las intenciones terroristas de un (supuesto) grupo que nunca ha actuado todavía, y por lo tanto no aparece como una contingencia sobre la que apostar, ya sea porque, aun existiendo, no ha intervenido en el mercado hasta ahora para enriquecerse o despistar y matar. 
Debería pues estar claro que la idea del Pentágono no sólo podría ser utilizada torticeramente por los propios terroristas; sino que además, aun suponiendo la posible ausencia de inteligencia oportunista, no deberíamos fiarnos de las probabilidades de actos terroristas que surgirían en ese mercado.

\subsection{Holgura ${ }^{6}$}

Continuando con los comentarios semifilosóficos con los que cerraba la sección anterior voy a insistir en la fragilidad posible del sistema de mercado con la intención de poner de manifiesto la dificultad intrínseca de medir el coste económico del terrorismo para una sociedad determinada. Volvamos de nuevo al problema de maximizar una función de bienestar social (como por ejemplo la suma de las funciones de utilidad de todos los individuos) con sujeción a las restricciones de recursos de acuerdo con las cuales lo que se necesita de cada bien para producir la cantidad de uno determinado, de acuerdo con una función de producción de coeficientes fijos, ha de ser menor o igual que la cantidad disponible. De este problema matemático surgen unas constantes, llamadas precios sombra, que son unos indicadores de la escasez social y solucionan el problema dual de minimizar, a esos precios, el coste de producir, con la tecnología indicada, un nivel dado de bienestar social.

Lo interesante de ese ejercicio es que, cuando uno de esos precios sombra es cero, quiere decir, no que no hay que pagar por él, sino que es socialmente abundante ya que un pequeño incremento en su cantidad no nos sirve para incrementar el bienestar. En términos de holgura diríamos que, en lo que concierne a ese recurso en particular, no tenemos que preocuparnos mucho ya que, en definitiva, una pequeña perturbación de su cantidad disponible no va a cambiar la asignación de bienes. Es decir que, en presencia de esa holgura, la asignación de bienes (que es lo que le preocupa a los economistas) deja de ser frágil. Más en concreto, lo que pretendo es aplicar esa intuición económica de la holgura tanto al terrorismo de nuevo cuño como a la crisis financiera que vivimos.

Respecto al nuevo terrorismo suicida que hace su presentación en el atentado de las torres gemelas de NY la primera parte de esta sección nos ha introducido a las categorías de fragilidad, transparencia, saturación y movilización total que parecen caracterizar a una sociedad como la nuestra en la que surge el terrorismo suicida. En ninguno de los autores citados se habla de holgura; pero me parece obvio que la parte agónica de sus ideas tiene que ver con su falta.

Ya hemos comentado que esos comentarios filosóficos no parecen tener nada que ver con la Economía pero que hay algunas nociones abstractas y profundas de la manera de pensar económica, como la racionalidad y el

${ }^{6}$ Este apartado corresponde a lo expuesto en Urrutia (2007). 
mercado, que reciben nueva luz de estas consideraciones filosóficas y que ahora nos vuelven a confrontar con la holgura.

Ya nos hemos extendido sobre la noción de mercado de forma que ahora diremos algo sobre esa racionalidad. Mi opinión nada favorable sobre el diseño muestra mi recelo hacia la sobredosis de racionalidad ya que, como pasa en el diseño, todo tiene su función y no hay nada arbitrario. La moraleja, en mi opinión, es que hay que ser sabios, no sólo racionales, para saber prescindir del uso de la escueta racionalidad funcional en aras de una reserva de capacidad creativa a ejercer en circunstancias no previstas. La racionalidad excesiva, que podríamos relacionar con la transparencia total, podría generar otra vez una enorme fragilidad. Y aquí entra la holgura como algo necesario.

En la medida en que el terrorismo puede entenderse como la puesta en práctica del odio y éste esté sujeto a una cierta dinámica generada quizás por el intento de alcanzar grandes fines políticos podemos considerar que cabe hablar de innovaciones hechas posibles por la holgura existente en la cantidad de recursos necesarios para llevarlo a cabo a su nivel de equilibrio. Esta holgura permite innovaciones que pueden trabajar en cualquier sentido disminuyendo o aumentando el precio sombra de los recursos necesarios para poner el terrorismo en práctica. Por esta razón un poco técnica nos encontramos con la imposibilidad de valorar con precisión el coste económico que el terrorismo impone. Sabemos acercarnos al valor de la producción a precios de mercado que se deja de producir, por ejemplo, por el cierre de una cierta empresa; pero no podemos saber cuál es el verdadero coste social de una decisión tal ${ }^{7}$.

\section{Medidas paliativas}

Si queremos explorar las posibles medidas paliativas de los efectos del terrorismo no tenemos más remedio que abandonar el marco del análisis de equilibrio general y pasar a consideración de equilibrio parcial. La razón es que toda propuesta de medida paliativa ha de ser considerada como una cuestión de estática comparada y este tipo de cuestiones rara vez reciben una respuesta concreta cuando se efectúan en un marco tan general que hay que tener en cuenta demasiados cambios. Por suerte contamos con un par de artículos de Frey y Luechinger (2003 y 2004) que se mueven con el ámbito adecuado y que plantean una alternativa general que es imposible de ignorar. Ahora entraremos en ella sin distinguir entre diversos tipos de terrorismo aunque esta diversidad deberá ser mencionada al menos para mostrar la dificultad de optar por unas medidas u otras.

${ }^{7}$ El magnífico e ingenioso trabajo de Abadie y Gardeázabal (2003) no está exento de esta dificultad. 
Frente al terrorismo debemos optar por el palo o la zanahoria o, naturalmente, diversas combinaciones de uno y otro. Comenzamos por estudiarlos por separado. Las estudiamos en el contexto del siguiente gráfico que corresponde a la toma de decisión terrorista (individual en principio aunque bien podríamos pensar en el grupo) respecto a cuánto adquirir de terrorismo $(\mathrm{T}) \mathrm{o}$ de otros bienes $(\mathrm{O})$ de acuerdo con sus gustos y deseos y dentro de las posibilidades que ofrecen la asignación y los precios del equilibrio general. El gráfico siguiente muestra, en el espacio (O-T) la utilidad del terrorista representado por una familia de curvas de indiferencias (de la que sólo se muestra una) y la restricción presupuestaria cuyo ángulo con el eje horizontal mide el coste del terrorismo en términos del resto de los bienes. Este costo depende del costo de los medios necesarios para actuar en contra de la vida o de la hacienda o de la libertad de los demás incluyendo el costo esperado, si es atrapado, en años de cárcel. La forma de las curvas de indiferencia depende naturalmente del tipo de terrorista del que se trata. Un terrorista o un grupo terrorista puede ser tan fanático que para compensar una disminución de su actividad exige un enorme volumen de otros bienes. En este caso la Relación Marginal de Sustitución es tan pequeña que gráficamente la curva de indiferencia representativa del mapa será prácticamente vertical. En cambio, si el fanatismo no caracteriza al grupo terrorista, sino que más bien se trata de un grupo que llamaríamos político y que se siente no escuchado, una reducción de la actividad terrorista de un cierto tamaño será compensable con muchos menos bienes que en el caso del fanático. El punto de tangencia entre la curva de indiferencia y la recta que delimita el conjunto presupuestario determina el equilibrio (parcial) en términos de consumo de otros bienes $\left(\mathrm{O}^{*}\right)$ y actividad terrorista $\left(\mathrm{T}^{*}\right)$.

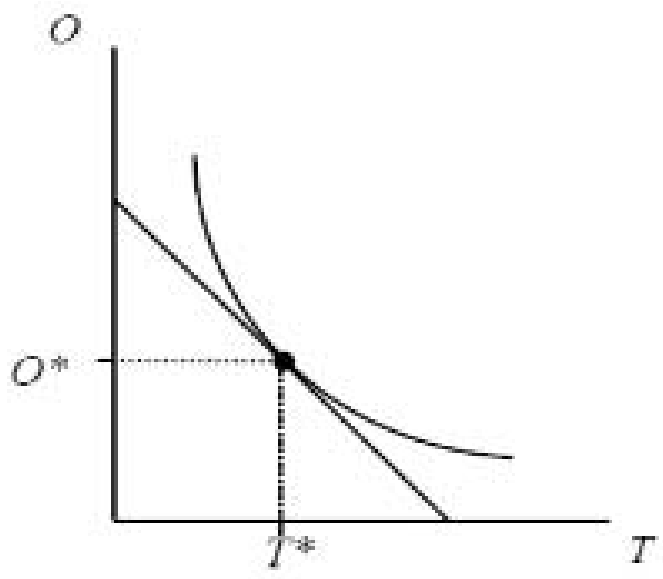




\subsection{La estrategia del palo}

En este contexto examinamos primero las medidas paliativas basadas en la amenaza de la pena correspondiente: la estrategia del palo. Cualquiera que sea su forma, esta amenaza incrementa el coste esperado del terrorismo de forma que la recta delimitadora del conjunto presupuestario varía de tal forma que el coste del terrorismo en términos de otros bienes aumenta. Como se ve en la siguiente figura, el terrorista, dadas sus preferencias, cambia su decisión a perpetrar menos actos terroristas $\left(\mathrm{T}_{1}^{*}\right)$ y hacerse con más de los otros bienes que antes $\left(\mathrm{O}_{1}^{*}\right)$

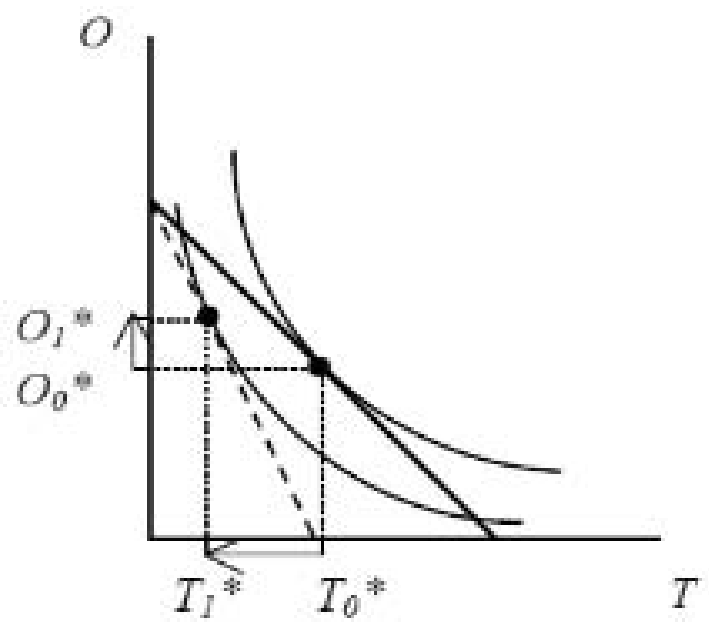

Notemos que estas medidas de tipo represivo son tanto más efectivas cuanto menos fanáticos son los terroristas. Con unas curvas de indiferencia cuasi-verticales el incremento de otros bienes tendría que ser tan enorme que no sería razonable pensar que un incremento de las penas o una imposibilidad de redimir penas fuera a disminuir significativamente la actividad terrorista. Tal como muestra la figura cuando el fanatismo no es enorme este tipo de incremento del coste puede ser significativamente efectivo. Notemos de pasada que hay un límite a esta estrategia del palo. La pena de muerte podría no servir para nada o incluso incrementar la actividad terrorista ya que, una vez cometido un acto que acarrea la pena de muerte, no hay amenaza alguna que reduzca el incentivo del terrorista a matar. 


\subsection{La estrategia de la zanahoria}

Pasemos ahora a considerar las posibilidades de la zanahoria. A diferencia de las medidas amenazadoras, nos encontramos ahora con dos tipos de medidas basadas ambas en la benevolencia o el «buenismo» que dirían otros. Como dirían Frey y Luechinger (2003) dejamos de considerar al mundo como un mundo a lo Becker (1968) y mirarlo como un mundo a lo Boulding (1968 y 1970) o, equivalentemente, pasar de una economía basada en el odio a una economía basada en el amor. Para aplicar este punto de vista recordemos con Schelling (1991) cuáles son las tres finalidades específicas del terrorismo: hacer publicidad de la causa (sea ésta la que sea), descentralizar al sistema político y dañar la economía de ese sistema político. Dadas estas finalidades, podemos, desde la benevolencia o el amor, dificultar su obtención o incrementar el coste de oportunidad de tratar de conseguirlo.

5.2.1. La obtención de las finalidades destacadas por Schelling (1991) se dificulta o bien no dando excesiva publicidad a las acciones terroristas o dejando sembrada la duda de su autoría o bien descentralizando el sistema político y económico. En el primer caso la consecución de los objetivos políticos se hace más difícil en cuanto un sistema con un mayor número de centros de decisión es más inmune. En el caso económico porque un sistema económico descentralizado es más resiliente. Con medidas de este tipo la RMS de las curvas de indiferencia cambia de forma que se hacen más planas. El siguiente gráfico, representa la consecuencia de este cambio. Como se ve la actividad terrorista disminuye.

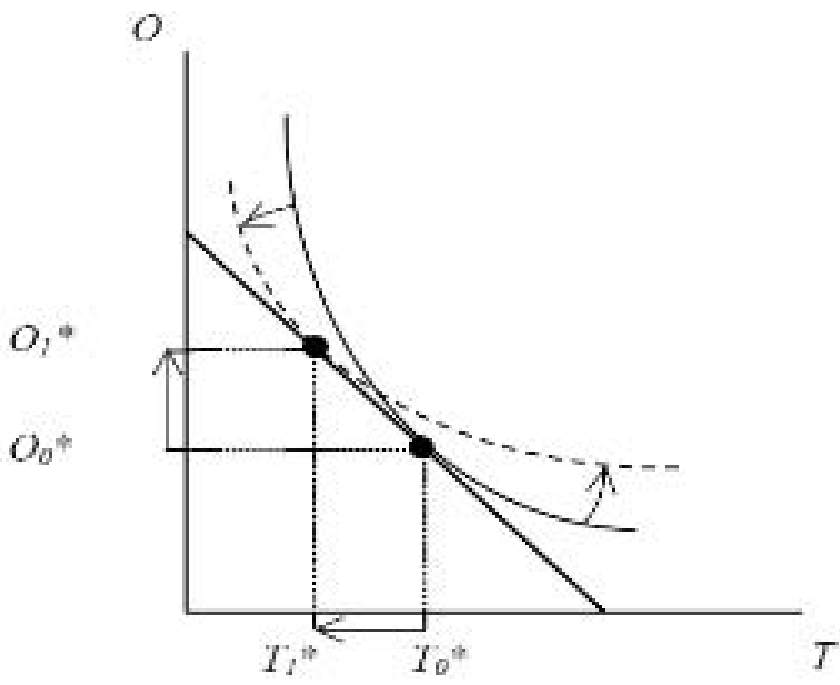


5.2.2. Pensemos ahora en incrementar el coste de oportunidad de la actividad terrorista. Es decir, incrementemos lo que pueden ganar dejando la actividad armada. Frey y Luechinger (2003) mencionan programas especiales para que los terroristas (o más bien para los que se muevan en círculos cercanos, pero todavía no han pasado a la acción) visiten otros países y posiblemente asistan a cursos que les abran la mente a otras posibilidades alternativas. Pero no sólo eso; sino que también mencionan la posibilidad de poner en marcha programas de testigos protegidos que sirvan para poder condenar a otros terroristas o la de abrir la posibilidad a su participación política eliminando de golpe una de las quejas más habituales de los grupos terroristas. Este movimiento del coste de oportunidad puede también representarse gráficamente mediante la ampliación del conjunto presupuestario tal como se indica en la siguiente y última figura.

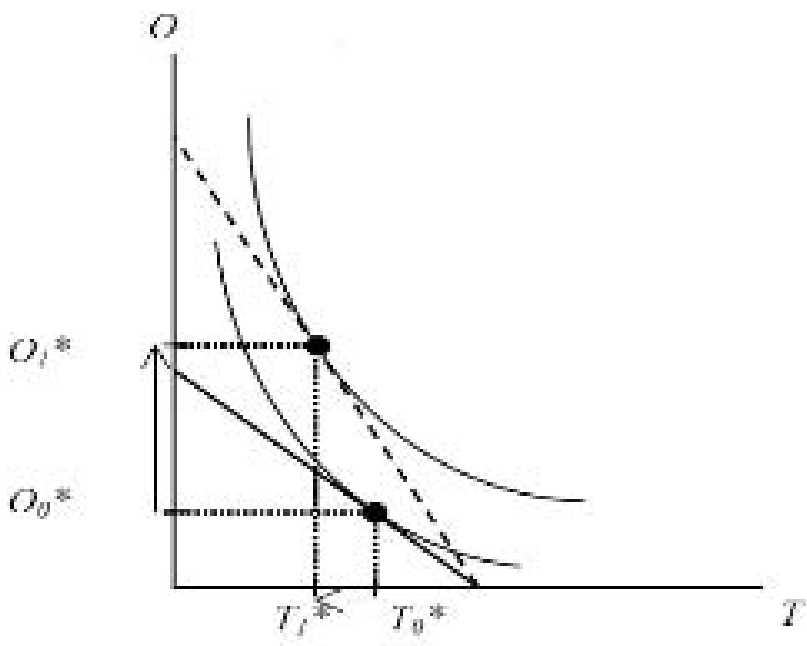

\subsection{Dificultades políticas}

Una vez pasada revista de algunas medidas paliativas, ya estén basadas en el palo o en la zanahoria, no podemos dejar de llamar la atención sobre las dificultades «políticas» de implementar unas y otras. Las medidas basadas en el incremento del costo pueden chocar con la sensibilidad de los defensores de los derechos humanos, y las medidas basadas en la benevolencia pueden ser rechazadas tanto por las víctimas como, en algunos casos, por los propios terroristas beneficiarios, que se sienten como traidores al grupo. Por estas razones, que merecerían una atención más detallada, parece que, al 
nivel de conocimiento teórico y empírico al que nos movemos y ante la variedad de terrorismos y de formas en el desarrollo de cada uno, sólo cabe aceptar un cocktail de medidas que sean tomadas con el mayor consenso posible y en un ambiente de franca transparencia.

\subsection{Las razones de la mediación}

Por estas razones parece imposible evitar una cierta reflexión sobre las posibilidades de la mediación entre las partes implicadas. Un tema vidrioso sobre el que sólo puedo repetir lo que ya dije hace tiempo y que se basa en argumentos económicos que creo tienen interés en sí mismos (ver Urrutia 2005).Tanto el grupo mayoritario y poderoso, como el minoritario y débil (en cuyo seno rige el terrorismo), adolecen de un cierto sesgo cognitivo, un fenómeno psicológico incorporado hacía tiempo al análisis económico (ver Rabin 1998).

Pensemos en la mediación en un contexto en el que las partes adolecen de este sesgo cognitivo. Ese mediador es, para un economista, como un principal que ha de recoger información, señales y evidencias de un cierto número de agentes con cada uno de los cuales establece un contrato que especifica los incentivos que se le proporciona para que actúe de acuerdo con los intereses del principal. El problema de cómo es el contrato óptimo ha sido estudiado profusamente por los economistas en escenarios diversos. Sin embargo, no ha sido estudiado en una situación en la que el principal sabe que el agente adolece de sesgo confirmatorio y no lo ha sido, seguramente, porque la economía lidia sistemáticamente con racionalidad perfecta, un supuesto que parecería ser violado por ese sesgo confirmatorio. Sin embargo, Rabin y Schrag (1999) han explorado este territorio recientemente con resultados que paso a glosar y que espero resulten bastante intuitivos.

Primero, no sería óptimo que el mediador tratara de extraer muchas señales, o evidencias, de cada agente o, en nuestro caso, de cada sujeto contactado para obtener información de lo que pasa. Y esto porque las últimas señales recogidas por dicho agente puedan estar sesgadas por las previas que haya recibido y que ha entendido, mal o bien, como confirmadoras de su concepción a priori de la situación. Segundo, para obtener un determinado volumen de evidencias que el mediador crea necesitar, quizá no sea bueno que se obtenga de un solo sujeto, sino quizá sea mejor que dicho volumen de evidencias se obtenga extrayendo un poco de información de cada uno de los miembros de un grupo numeroso de agentes. Igual que antes esto es así porque las últimas informaciones adquiridas por un agente no son muy informativas, ya que su interpretación está sesgada por la concepción que se ha ido formando a partir de las señales obtenidas con anterioridad. Tercero, puede ser arriesgado que un mediador hable con expertos ya que las evidencias que éstos puedan aportar pueden estar, una vez más, sesgadas por sus 
propios prejuicios. Sería mejor que el mediador adoptara una especie de regla de mayoría, sin ponderar cada opinión por el grado de firmeza de su emisor. Esta firmeza puede ser debida al sesgo confirmatorio y no revelar de hecho ninguna información importante.

Me parece natural que un Estado democrático no admita una mediación internacional en un contencioso interno, tanto más si ese Estado niega la existencia del conflicto. Pero, aun así, creo que se me admitirá que antes de que mueran inocentes merece la pena explorar soluciones imaginativas. La que se sigue de lo anterior, y porque está basada en ideas aburridas de psicólogos y economistas, no es imaginativa, aunque sí, quizás, ingenua. Podría concebirse, en efecto, un panel formado por un número a determinar de ciudadanos heterogéneos escogidos entre la población de presuntos apolíticos e incluso abstencionistas. Este panel sería sometido a varias horas de exposición de ideas de cada parte involucrada en el conflicto. A continuación, este panel acabaría agregando sus opiniones en lo que nos comprometeríamos a admitir como la descripción fidedigna de lo que está pasando.

Ya sé que esta propuesta sentará muy mal a los políticos profesionales, a quienes orilla y quienes objetarán que es imposible de llevar a la práctica. También sé que tampoco gustará a quienes se creen en la obligación de defender la primacía de la política como emanación de la razón ilustrada. Quizá ambos están en lo cierto y yo esté equivocado al extraer conclusiones precipitadas de una forma irracional de sesgo psicológico, pero si ese sesgo existe, y parece que así es, la bienintencionada utilización de la razón debe afinarse si quiere servir de algo. He ahí el problema. Si se quiere solucionar, la alternativa me parece clara: o propuestas del corte de la perfilada aquí, o en su defecto un verdadero mediador. Parecería que este dilema ofrece una buena oportunidad para políticos de nuevo cuño.

\section{Conclusiones}

Llegados a este punto sólo queda recordar la intención del trabajo, hacer una especie de resumen que ponga orden en el tratamiento a veces confuso y, como colofón, concluir contundentemente.

La intención de este trabajo era la de, a semejanza de lo que Becker intentó en Crime and Punishment (1968), tratar de modelizar en términos de teoría económica el fenómeno del terrorismo. En la medida de lo posible han sido eliminadas del texto referencias psicológicas, sociológicas, políticas o literarias y el tratamiento ha sido lo suficientemente abstracto de manera que, en general y con pocas excepciones, no se ha hecho referencia alguna a movimientos terroristas específicos

Después de esta confesión de intenciones podemos hacer un resumen apretado. El tratamiento teórico-económico aparece en todas las secciones en 
el sentido de que en todas ellas se utilizan herramientas usadas profusamente por la teoría económica. Los juegos evolutivos han sido utilizados para dar una idea de cómo una sociedad puede escindirse en distintos grupos, cada uno de los cuales se caracteriza por pautas de conducta específicas. Una situación así puede seguir evolucionando hacia la fraternidad en donde las pautas de conducta se homogenizan o puede atrincherarse en sus diferencias identitarias. Cuando éste es el caso puede surgir el odio entre comunidades identitarias en buena parte alimentado por falsos mitos cuyo surgimiento puede ser explicado mediante una aplicación relativamente sencilla de costes y beneficios que, especialmente cuando se pone en conexión con la persecución del poder, tal como hizo Glaeser (2005), es bastante novedoso. En cuanto podemos hablar, siquiera metafóricamente, de oferta y demanda de odio, estamos en disposición de introducir la actividad terrorista (en la que el odio desemboca) en el contexto de un sistema económico de mercado. Esto permite unas incursiones en terrenos filosóficos que, a su vez, conducen a una forma indirecta y posiblemente más reveladora, de entender la fragilidad del sistema de mercado, rechazar algunas ideas extremas, como la instauración de mercados de futuros sobre actos terroristas, ideas éstas fáciles de desmontar, y criticar los intentos a menudo brillantes de cuantificar los efectos económicos del terrorismo. Además hemos podido discutir medidas paliativas controvertidas y a veces muy difíciles de poner en práctica como es el caso de la mediación. Por grande que sea el nivel de abstracción en que este trabajo se haya movido, hubiera parecido incluso exótico no hacer alguna referencia al tema del nacionalismo y su relación con el terrorismo y así se ha hecho utilizando la noción de fraternidad introducida desde el principio y que ha resultado suficiente para desmontar esa posible relación.

Y termino con un párrafo contundente que repite el final de Urrutia (2005, 160-1). El terrorismo mata la fraternidad. La fraternidad es compleja. No se puede vencer al terrorismo con principios (aunque éstos sean suficientes para rechazarlo). Hace falta reconstruir la fraternidad y esto exige soluciones complejas (que a veces parecen ambiguas) y el respeto a las convenciones ya existentes.

\section{REFERENCIAS}

Abadie, Alberto y Gardeázabal, Javier. «The Economic Costs of Conflict: A Case Study of the Basque Country», American Economic Review, 93, 1 (2003): 11332.

Alesina, Alberto y Spolaore, Enrico. The Size of Nations, Cambridge, Mass.: MIT Press, 2003.

Baudrillard, J. «L'esprit du terrorisme», Le Monde, 3 de noviembre de 2001.

Becker, G. S. «Crime and Punishment: An Economic Approach», Journal of Political Economy, 76 (1968): 169-217. 
Blackmore, Susan J. The Meme Machine, Oxford; New York: Oxford University Press, 1999.

Borradori, G. La filosofía en una época de terror, Madrid: Taurus, 2003.

Boulding, Kenneth E. Beyond Economics; Essays on Society, Religion, and Ethics, Ann Arbor: University of Michigan Press, 1968.

Boulding, Kenneth E. Economics as a Science, New York: McGraw-Hill, 1970.

Dawkins, Richard. The Selfish Gene, Oxford; New York: Oxford University Press, 1989.

De la Calle, L. y Sánchez-Cuenca, I. «What We Talk About When We Talk About Terrorism», Politics and Society, 39 (2011): 451-472.

Domènech, Antoni. «... y fraternidad», Isegoría, 7 (1993): 49-77.

Elster, Jon. The Cement of Society: A Study of Social Order, Studies in Rationality and Social Change, Cambridge; New York: Cambridge University Press, 1989.

Frey, Bruno S. y Luechinger, Simon. «Decentralization as a Disincentive for Terror», European Journal of Political Economy, 20, 2 (2004): 509-15.

Frey, Bruno S. y Luechinger, Simon. «How to Fight Terrorism: Alternatives to Deterrence», Defense and Peace Economics, 14, 4 (2003): 237-49.

Friedman, Daniel. «Evolutionary Games in Economics», Econometrica, 59, 3 (1991): 637-66.

Glaeser, Edward L. «The Political Economy of Hatred», Quarterly Journal of Economics, 120, 1 (2005): 45-86.

Glucksmann, André. Dostö̈evski à Manhattan, Paris: Robert Laffont, 2002.

Lertxundi, Anjel. Vida y otras dudas, Irún: Alberdania Editora, 2010.

Llussá, Fernanda y Tavares, José. «The Economics of Terrorism: A Synopsis», Economics of Peace and Security Journal, 2, 1 (2007): 62-70.

Rabin, Matthew. «Psychology and Economics», Journal of Economic Literature, 36, 1 (1998): 11-46.

Rabin, Matthew y Schrag, Joel L. «First Impressions Matter: A Model of Confirmatory Bias», Quarterly Journal of Economics, 114, 1 (1999): 37-82.

Reinares, Fernando. Terrorismo y Antiterrorismo, Barcelona: Paidós, 1998.

Sánchez-Cuenca, I. y De la Calle, L. «Domestic Terrorism: The hidden side of Political Violence», Annual Review of Political Science, 12 (2009): 12-31.

Schelling, T. «What Purposes Can International Terrorism Serve?», en Violence, Terrorism and Justice, editado por R. G. Frey and C. W. Morris, Cambridge: Cambridge University Press, 1991.

Schlink, B. El fin de semana, Barcelona: Anagrama, 2011.

Semprún, J. Netchaiev ha vuelto, Barcelona: Tusquets, 1998.

Sloterdijk, P. Temblores del aire. En las Fuentes del Terror, Valencia: Pre-textos, 2003.

Urrutia, J. «Una reconstrucción de la fraternidad aristotélica mediante la teoría de los juegos evolutivos», Telos, Revista Iberoamericana de estudios Utilitaristas, 9 (2000): 89-120.

Urrutia, J. «Terrorismo, Filosofía, Economía y Nacionalismo», 2003a. Disponible en http://juan.urrutiaelejalde.org/articulos/terrorismo.html

Urrutia, J. «Futuros sobre actos terroristas, Directamente en la red», 2003b. Disponible en http://juan.urrutiaelejalde.org/articulos/cotizaciones.htm

Urrutia, J. La mirada del Economista, Madrid: Biblioteca Nueva, 2005. 
Urrutia, J. «Holgura», Expansión, 2 de octubre de 2007.

Urrutia, J. «La potencialidad conceptual de la Fraternidad, Identidad y Rebeldía», 2008. Disponible en http://juan.urrutiaelejalde.org/la-potencia-conceptual-de-fraternidad-identidad-y-rebeldia

Urrutia, J. El capitalismo que viene, Madrid: Ediciones del Cobre y Sociedad de Las Indias Electrónicas, 2009.

Wieviorka, M. La violence, París: Baland, 2005.

Zulaika, J. y Douglas, W. A. Terror and Taboo: the follies, fables and faces of terrorism, London: Routledge, 1996. 